\title{
THE SEXUAL CYCLE OF A SEASONALLY BREEDING MAMMAL, THE ROEBUCK (CAPREOLUS CAPREOLUS)
}

\author{
R. V. SHORT AND T. MANN \\ A.R.C. Unit of Reproductive Physiology and Biochemistry, and \\ Department of Veterinary Clinical Studies, University of Cambridge
}

(Received 15th February 1966)

Summary. We have studied the antlers and male reproductive organs of thirteen roebucks, shot at approximately monthly intervals throughout the year. The roebuck is a seasonally breeding mammal that is in rut from mid-July to mid-August. Antlers 'in velvet' begin to develop in January, and the velvet is shed in March or April. The animal then remains in 'hard horn' until November or December, when the antlers are cast.

The testes are at their most inactive state in January, when there is no spermatogenic activity and a very low content of testosterone. By midFebruary, the testicular testosterone content has risen considerably, and primary spermatocytes are to be seen in the enlarging seminiferous tubules. The testosterone content of the testis remains high until the beginning of the rut, but falls precipitously towards the end. Spermatogenesis is not finally completed until April or May, and, although it continues for several weeks after the end of the rut, there is a highly significant decline in testis tubular diameter that coincides with the fall in testosterone content. Thus spermatogenesis and androgenesis are closely related at the beginning and end of the sexual cycle, suggesting that FSH and LH secretion by the pituitary gland normally go hand-in-hand.

The seminal vesicles secrete fructose, sorbitol, inositol and citric acid. Although there is a significant correlation between testicular testosterone and vesicular fructose and citric acid, the correlation coefficients are not high. This is probably because the seminal vesicles do not respond until some weeks after the onset of testosterone production in the spring, and their secretion declines less rapidly than testicular testosterone after the end of the rut.

These endocrine changes are in accord with the seasonal changes in antler growth, which are known to be under endocrine control. Shedding of the velvet occurs soon after the testicular testosterone levels have risen in the spring, and casting of the antlers in late autumn coincides with extremely low testicular testosterone levels. 


\section{INTRODUGTION}

The changes in the male reproductive organs at the time of puberty have been studied in some detail in man and domestic and laboratory animals; less is known about the changes which occur seasonally or at the time of senescence in these species. The cyclical growth and regression of the male reproductive organs in seasonal breeders has not been studied in anything like the same detail. Such animals are nevertheless of fundamental interest, since they can provide information about the changing exocrine and endocrine function of the testis in relation to changes in pituitary gonadotrophic activity, especially at the beginning and end of the breeding season.

We therefore decided to study the reproductive cycle of the roebuck (Capreolus capreolus), and a preliminary note describing some of the findings has already been published (Short \& Mann, 1965). The roe deer is a small animal, the adult buck only weighing 20 to $25 \mathrm{~kg}$. It is indigenous to Europe, and fairly widely distributed at the present time throughout the British Isles (Taylor Page, 1962). The rut occurs from about mid-July to mid-August, and the antlers are cast in November or December. New antlers 'in velvet' begin to grow almost at once, the velvet being shed in March or April of the following year; the animal then remains in 'hard horn' throughout the summer months, from April to the following November.

The antlers of deer provide a convenient external indicator of androgenic activity, since casting of the antler can be induced by castration, and shedding of the velvet by injections of testosterone (Tandler \& Grosz, 1913; Wislocki, 1943; Wislocki, Aub \& Waldo, 1947). We have therefore attempted to correlate the stage of antler development with our biochemical studies of the male gonads and accessory organs.

\section{MATERIAL AND METHODS}

Thirteen fully grown bucks were shot at approximately monthly intervals from February 1964 to January 1965 on Forestry Commission land around Thetford in Suffolk. The weights of the animals, the dates when shot and the stage of antler development are listed in Table 1. The testes were cut off and placed in a polythene bag on ice in a thermos flask within about $30 \mathrm{~min}$ of the death of the animal. The whole carcase was then taken to the laboratory and a detailed dissection commenced within $3 \mathrm{hr}$ of death.

The testes, epididymides, ampullae of the vasa deferentia, seminal vesicles and pituitary gland were dissected out and weighed. Pieces of all these organs, except the pituitary, were then fixed in Bouin's solution for subsequent histological examination. The remaining pieces of testis, ampulla and seminal vesicle, and the anterior lobe of the pituitary gland were frozen at $-20^{\circ} \mathrm{C}$ until they could be assayed. An investigation of the gonadotrophin content of the pituitary glands is still in progress.

\section{Histology}

After embedding in paraffin, sections were cut at 8 to $10 \mu$ and stained with haematoxylin and eosin. A number of testis sections were stained by the periodic acid-Schiff (PAs) technique to show the developing acrosome in early spermatids. 


\section{Testosterone determinations}

The assay procedure was basically similar to the one described previously by King, Short, Mutton \& Hamerton (1966), for the extraction of testosterone and other neutral and phenolic steroids from equine testes.

An internal isotope standard of $7-{ }^{3} \mathrm{H}$ testosterone $(0.05 \mu \mathrm{c} / 0.017 \mu \mathrm{g}$; the Radiochemical Centre, Amersham, Bucks.) dissolved in $0.1 \mathrm{ml}$ benzene was added to 4 to $15 \mathrm{~g}$ frozen testicular tissue in an M.S.E. Atomix, and the tissue homogenized three times with $100-\mathrm{ml}$ portions of absolute methanol. Each homogenate was centrifuged, the supernatant decanted, and the precipitate re-homogenized with fresh methanol.

\section{TABLE 1}

DATA RELATING TO THE WEIGHT OF THE ROEBUCKS AND STATE OF THEIR ANTLERS

\begin{tabular}{l|c|l}
\hline $\begin{array}{c}\text { Animal No. } \\
\text { and date when shot }\end{array}$ & Weight $(\mathrm{kg})$ & \multicolumn{1}{|c}{ State of antlers } \\
\hline 1. 19th January 1965 & $23 \cdot 1$ & In early velvet \\
2. 11th February 1964 & $20 \cdot 9$ & In velvet \\
3. 4th March 1964 & $20 \cdot 9$ & In velvet \\
4. 18th March 1964 & $25 \cdot 4$ & In velvet \\
5. 31st March 1964 & $16 \cdot 8$ & Velvet just shed \\
6. 13th May 1964 & $20 \cdot 9$ & Hard horn \\
7. 17th June 1964 & $16 \cdot 3$ & Hard horn \\
8. 14th July 1964 & $19 \cdot 5$ & Hard horn \\
9. 11th August 1964 & $20 \cdot 4$ & Hard horn \\
10. 18th September 1964 & - & Hard horn \\
11. 1st October 1964 & $23 \cdot 6$ & $\begin{array}{l}\text { Hard horn, osteoclastic } \\
\text { activity around base of } \\
\text { antler pedicle }\end{array}$ \\
12. 15th November 1964 & $25 \cdot 9$ & $\begin{array}{l}\text { Hard horn, osteoclastic } \\
\text { activity around base of }\end{array}$ \\
& & antler pedicle \\
13. 18th December 1964 & $26 \cdot 3$ & Cast \\
\hline
\end{tabular}

The pooled methanolic extracts (approximately $300 \mathrm{ml}$ ) were evaporated to a volume of 10 to $20 \mathrm{ml}$ in a rotary evaporator. The concentrate was made up to $100 \mathrm{ml}$ with distilled water, and extracted twice with $200 \mathrm{ml}$ ethyl acetate. The combined ethyl acetate extracts were washed once with $10 \mathrm{ml}$ water and evaporated to dryness under reduced pressure. The residue was transferred to a centrifuge tube with several washings of ethyl acetate and methanol and finally redissolved in $10 \mathrm{ml} 70 \%$ methanol. This solution was refrigerated overnight at $-30^{\circ} \mathrm{C}$ and centrifuged at that temperature for $15 \mathrm{~min}$ at $100,000 \mathrm{~g}$. The supernatant was decanted and evaporated to dryness once more on the rotary evaporator.

The dry residue was transferred to a separatory funnel in $1 \mathrm{ml}$ ethanol $+25 \mathrm{ml}$ benzene $+25 \mathrm{ml}$ of 40 to $60^{\circ} \mathrm{C}$ b.p. light petroleum. This solution was then washed twice with $25 \mathrm{ml} 1.6 \% \mathrm{NaOH}$ to remove phenolic and polar 
compounds, and the alkali washings discarded. The benzene-petroleum ether solution was then washed neutral with water, evaporated to dryness and chromatographed on paper in a ligroin $-80 \%$ methanol system, together with standards of authentic testosterone and androstenedione. The testosterone area of the chromatogram was cut out, eluted with methanol, the eluate evaporated to dryness, and then acetylated overnight with $0.1 \mathrm{ml}$ acetic anhydride and pyridine $(1: 1)$. The acetylation product was then re-chromatographed in the same paper system, together with a standard of authentic testosterone. No attempt was made to quantitate the amount of androstenedione present; none was ever clearly visible on ultraviolet contact photography.

If a testosterone spot was clearly visible on photography of the chromatogram (i.e. more than $1 \mu \mathrm{g}$ steroid), final quantitation was carried out by ultraviolet spectrophotometry, readings being taken at 220, 240 and $260 \mathrm{~m} \mu$ against an eluted filter paper blank. One-tenth of the final testosterone acetate solution was saved for liquid scintillation counting.

In a few instances, where little or no testosterone was visible on the final paper chromatogram (animals 1, 2, 3, 4, 12 and 13), the eluate from the paper chromatogram was measured by gas chromatography in an F \& M model 400 Biomedical Analyser, equipped with a hydrogen flame detector. An internal standard of cholestane $(0.2$ to $0.8 \mu \mathrm{g})$ was added to each sample, an aliquot removed for liquid scintillation counting, and a portion of the remainder injected onto a 4 -ft column of $3.8 \%$ S.E. 30 at $230^{\circ}$ C. Quantitation was achieved by cutting out and weighing the peaks of testosterone acetate and cholestane traced on the chart recorder.

It is possible that this procedure may give an underestimate of the true testosterone acetate concentration in a few cases, since washed filter paper eluates occasionally contain material with a retention time identical to that of cholestane (Jeffrey, personal communication). Any such error in the present experiments is not likely to have been greater than about $30 \%$, if it occurred at all, and it would have been confined to samples $1,2,3,4,12$ and 13 .

The recovery rates were determined by counting an aliquot of the final testosterone acetate fraction in a Packard Tricarb liquid scintillation counter. The mean recovery rate was found to be $61 \%$, range 48 to $73 \%$. All the results were corrected for these extraction losses.

In order to obtain a more definitive identification of the testosterone measured in this study, the testosterone acetate fractions that had been measured spectrophotometrically were pooled, saponified by treatment with $1.6 \% \mathrm{NaOH}$ for $30 \mathrm{~min}$, and then oxidized by treatment with a $10 \%$ solution of chromium trioxide in pyridine. The reaction product was indistinguishable from authentic androstenedione in the paper and gas chromatographic systems already described. Thus there can be little doubt as to the specificity of this assay procedure for testosterone.

\section{Fructose and citric acid determinations}

The seminal vesicles and ampullae were analysed for fructose and citric acid as described by Lindner \& Mann (1960) for the bull seminal vesicles, except that, in addition to the two ethanol extractions for fructose, a third extraction 
was included so as to ensure a complete recovery of all the fructose from the vesicular and ampullary tissue.

\section{Chromatography of carbohydrates}

Confirmatory evidence for the occurrence of fructose as the main sugar in the roebuck seminal vesicle was obtained by paper chromatography, using pooled ethanolic extracts from three animals (shot from May to July). After removal of ethanol, an aliquot of the material was purified on an ion-exchange resin column composed of Amberlite IR-120[H $\left.{ }^{+}\right]$and Dowex AG-1 $\left[\mathrm{O} \mathrm{Ac}^{-}\right]$, and the eluate examined by descending paper chromatography using ethyl acetatepyridine-water ( $8: 2: 1$, by volume), as described by Mann \& Rottenberg (1966). The spots of fructose and other carbohydrates were located by the silver-spray method of Trevelyan, Procter \& Harrison (1950).

\section{Gross morphology}

\section{RESULTS}

The seasonal changes in the weights of the two testes (without the epididymides) and the two seminal vesicles are recorded in Text-fig. I, from which it can be seen that there was almost a five-fold increase in testes weight during the year, the maximal value coinciding with the end of the rut, and the minimal value occurring in the period December to January. The decline in testicular weight after the end of the rut was more abrupt than the increase preceding the rut.

The seasonal changes in the weight of the seminal vesicles were less pronounced, and somewhat more erratic. The lowest and the highest values differed only by a factor of two and a half.

The weight of the epididymides barely doubled during the year, reaching a maximum $(6.6 \mathrm{~g})$ at the end of the rut. The weights of the ampullae were extremely variable; however, the heaviest ampullae $(0.92 \mathrm{~g})$ were found at the end of the rut, and the smallest $(0.28 \mathrm{~g})$ in mid-January.

By contrast, pituitary weight bore no relationship whatsoever to the stage of the reproductive cycle, varying from 0.173 to $0.358 \mathrm{~g}$ at random throughout the year.

\section{Histology}

In mid-January, the testes were devoid of all signs of spermatogenic activity, the tubules being lined only by Sertoli cells and spermatogonia; the Leydig cells were not distinguishable as such in the intertubular tissue, and no spermatozoa were present in the epididymis.

A month later, in mid-February, a few primary spermatocytes could be seen in some of the tubules, but the Leydig cells were still indistinguishable. By mid-March, all the tubules contained primary spermatocytes, and some also contained secondary spermatocytes; the Leydig cells were beginning to be apparent in the intertubular tissue. The epithelium of the cauda epididymidis appeared to be sloughing off in places, although this may have been an artefact.

Two weeks later, at the end of March, all the tubules contained primary 
spermatocytes, many had secondary spermatocytes as well, and, in a few, early spermatids were recognizable after PAS staining; the Leydig cells were now quite distinct, having acquired an eosinophilic cytoplasm. Much of the epithelium of the caput epididymidis had sloughed off into the lumen of the tubules, whereas the epithelium of the cauda epididymidis was intact, but much folded. There were still no spermatozoa in either the testis or epididymis.

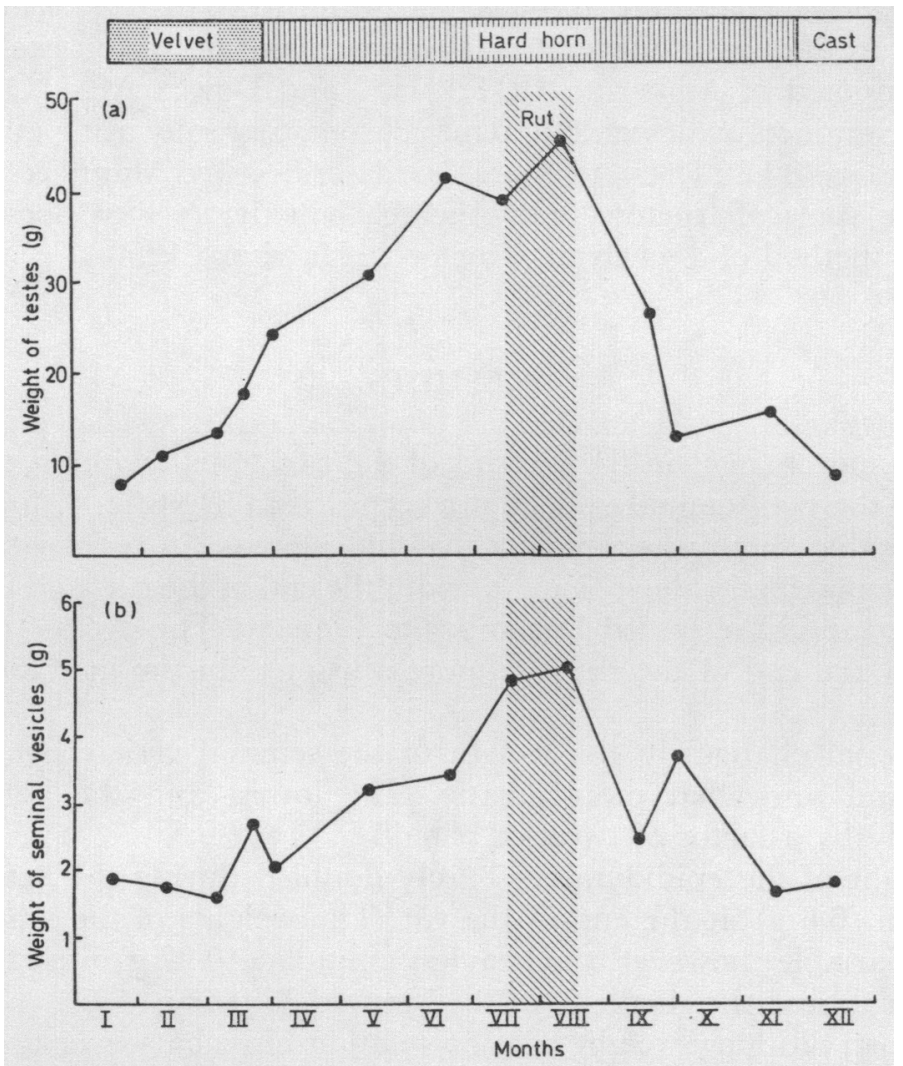

TEXT-FIG. 1. Seasonal changes in the weight of (a) testes, and (b) seminal vesicles of the roebuck. The period of rut is indicated by the vertical column; the state of the antlers (in velvet; hard horn; cast) by the horizontal bar at the top.

Six weeks later, by mid-May, spermatogenesis was already complete, with free spermatozoa lying in the lumina of most of the seminiferous tubules; the Leydig cells had now become quite prominent, and the tubules of the caput and cauda epididymidis were packed with spermatozoa. In mid-June, and mid-July (the beginning of the rut), the picture was similar, with very active spermatogenesis and well-developed Leydig cells. However in mid-August, at a time which many would regard as still during the rut, a striking change had taken place: spermatogenesis was still very active, but the Leydig cells had now become shrunken in appearance (see Pl. 1, Figs. 1 and 2). The epididymis was still full of spermatozoa.

A month later, in mid-September, spermatogenesis was still continuing, but in the tubular lumen there were many immature cells, probably secondary 
spermatocytes and spermatids. It was difficult to distinguish the Leydig cells at this stage. However, spermatozoa were still plentiful, especially in the cauda epididymidis.

By the beginning of October spermatogenesis appeared to be becoming more disordered. Although some tubules still appeared normal, others contained spermatids but no spermatocytes. The caput epididymidis was now devoid of spermatozoa, although an occasional spermatozoon could be found in the cauda, together with many immature cells and cellular debris (see Pl. 1, Fig. 3).

Six weeks later, in mid-November, spermatogenesis was virtually at a standstill. Very few spermatozoa or spermatids could be seen in the seminiferous tubules, and the secondary spermatocytes looked abnormal. The epididymis contained the occasional spermatozoon, but cellular debris and immature cells were also present in large amounts.

TABLE 2

SEASONAL CHANGES IN THE MEAN DIAMETER OF SEMINIFEROUS TUBULES IN THE ROEBUCK TESTES

\begin{tabular}{|c|c|c|}
\hline $\begin{array}{l}\text { Animal No. } \\
\text { and date when shot }\end{array}$ & $\begin{array}{c}\text { Mean tubular diameter } \\
(\mu) \pm S . E . M .\end{array}$ & $\begin{array}{l}\text { Duncan's multiple range test } \\
\mathrm{P}=0.05^{*} \quad \mathrm{P}=0.01^{*}\end{array}$ \\
\hline 1. 19th January 1965 & $95 \pm 2$ & \\
\hline 2. I1th February 1964 & $129 \pm 2$ & \\
\hline 3. 4th March 1964 & $148 \pm 2$ & \\
\hline 4. 18th March 1964 & $160 \pm 3$ & \\
\hline 5. 31st March 1964 & $158 \pm 3$ & \\
\hline 6. 13th May 1964 & $190 \pm 4$ & \\
\hline 7. 17th June 1964 & $226 \pm 5$ & \} \\
\hline 8. 14th July 1964 & $231 \pm 5$ & \\
\hline 9. 11th August 1964 & $183 \pm 3$ & \\
\hline 10. 18th September 1964 & $163 \pm 3$ & \} \\
\hline 11. 1st October 1964 & $158 \pm 4$ & c \\
\hline 12. 15th November 1964 & $149 \pm 3$ & \} \\
\hline 13. 18th December 1964 & $116 \pm 3$ & \\
\hline
\end{tabular}

* Two means differ if not covered by the same brace.

By mid-December the testis had regressed even further; the tubules were lined mainly by spermatogonia and Sertoli cells and contained only the remnants of spermatocytes and an occasional spermatid and spermatozoon. The epididymis likewise contained only the occasional spermatozoon, but much cellular debris.

Table 2 summarizes the changes in the diameter of the seminiferous tubules throughout the year. As can be seen from that Table, the tubular diameter underwent a highly significant increase from January to February, and then again from February to March. Maximal values were reached in mid-June and mid-July; by the end of the rut, in mid-August, there was already a highly significant decline in tubular diameter, in spite of the fact that the testis weight showed no such change (see Text-fig. 1). This decline in tubular diameter continued until the middle of January. 
Histological examination of the seminal vesicles revealed changes which were in line with the result of the gross morphological observations, but because of the diffuse lobulo-alveolar structure of the gland, it was not possible to make any strictly quantitative assessment of either the alveolar diameter or the epithelial height. In January and February, the epithelium was low columnar in type and the glandular lumen was very small. It was not until the middle of May that one began to see a noticeable enlargement of the lumen. By the beginning of the rut in mid-July, the lumen had become quite large and the epithelium was tall columnar in type, with centrally placed nuclei (Pl. 1, Fig. 4). By mid-September, the epithelium had started to regress.

An interesting finding made in the course of the histological examinations was the presence of spermatozoa in the lumen of the seminal vesicle during the months of March, May, August, September and November. The occurrence of spermatozoa in March and November was particularly interesting since at that time the testes showed no active spermatogenesis. In the March animal there were not even any spermatozoa to be found in the epididymis.

\section{Testosterone in the testes}

The seasonal changes in the concentration of testosterone are shown in Textfig. 2. The concentration was extremely low in January, but showed a marked increase by mid-February and then continued to be high, though variable, until the beginning of the rut. A dramatic fall occurred at the end of the rut in midAugust and after that the concentrations remained low throughout September, October, November and December.

When the results of testosterone determinations are expressed in terms of total testicular content instead of concentration, the rise during the period from January to mid-July appears less erratic and exhibits a more definite maximum at the beginning of the rut (Text-fig. 3). Furthermore, the fall at the end of the rut appears to be even more pronounced, and the values from September to December do not differ greatly from the value in January.

\section{Fructose and citric acid in the seminal vesicles and ampullae}

Both fructose and citric acid were identified as normal constituents of the seminal vesicles of the roebuck.

The seasonal changes in the concentration of vesicular fructose and citric acid in the buck are shown in Text-fig. 2, from which it can be seen that while the concentration of fructose started to rise in mid-March and reached a peak

\section{EXPLANATION OF PLATE 1}

Fig. 1. Intertubular tissue of testis from Buck No. 8, shot 14 th July 1964 at the beginning of the rut. Note well-developed Leydig cells (arrowed), $\times 600$.

Fig. 2. Intertubular tissue of testis from Buck No. 9, shot 11 th August 1964 at the end of the rut. Note shrunken, inconspicuous Leydig cells (arrowed). $\times 600$.

Fig. 3. Cauda epididymidis of Buck No. 11, shot 1st October 1964. Note occasional spermatozoon (arrowed) and many immature cells. $\times 600$.

Fig. 4. Seminal vesicle of Buck No. 8, shot 14th July 1964 at the beginning of the rut. The alveoli are filled with secretion, and lined by a tall columnar epithelium with centrally placed nuclei. $\times 73$. 
PI ATE I

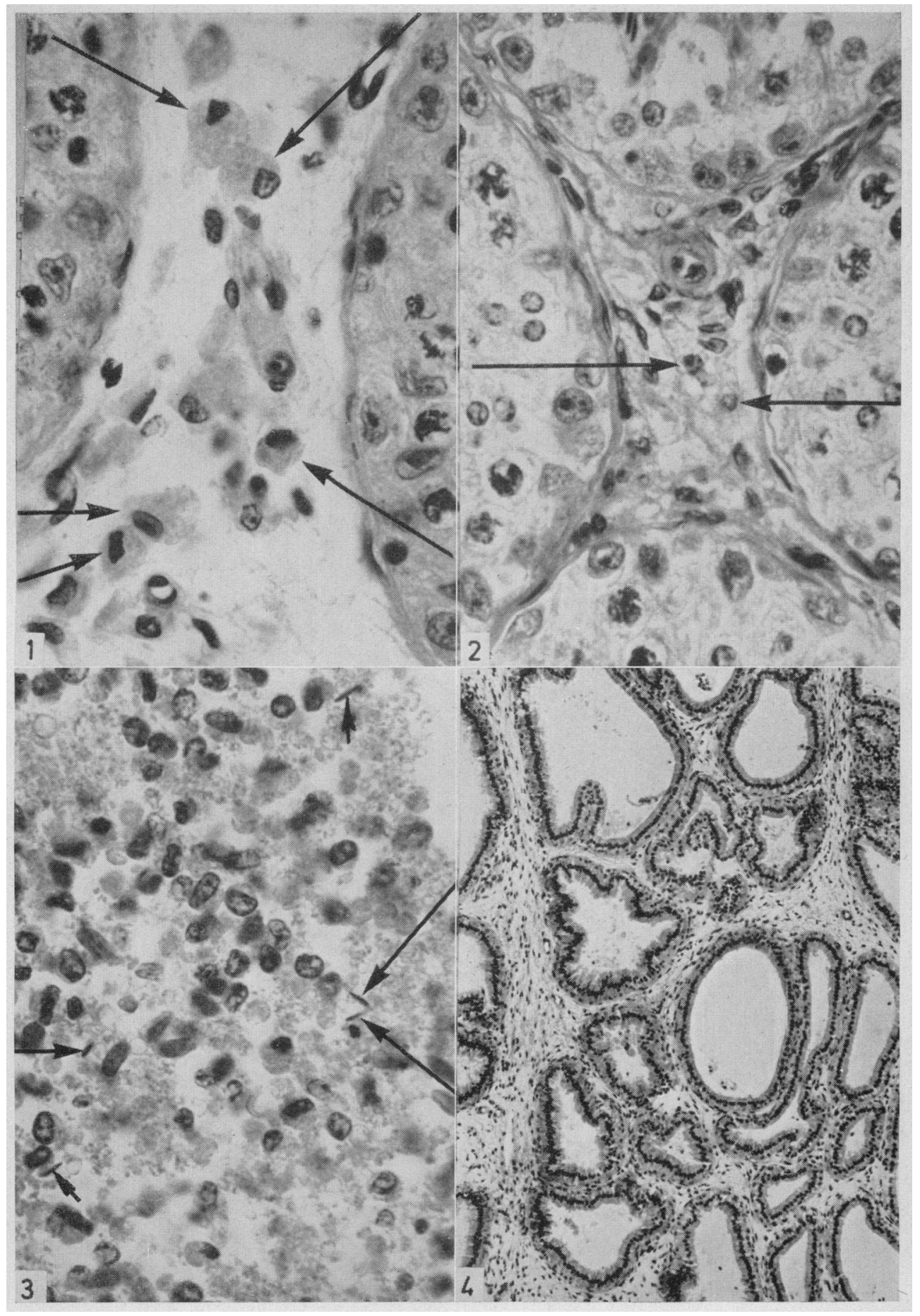

(Fiaing p. 344) 
PIATE 2

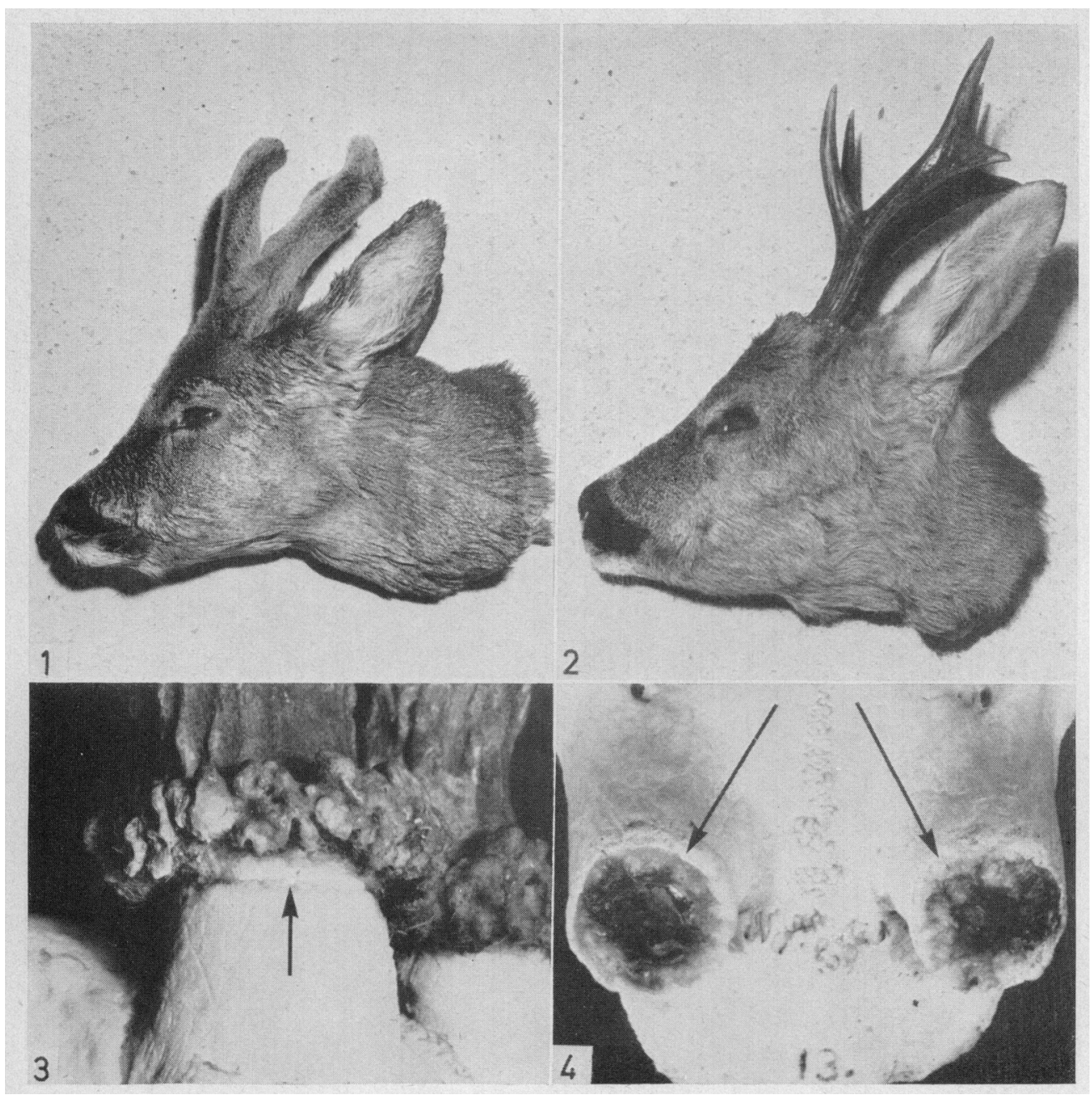

lix: 1. Buck No. 2, shot 11th February 1964, with antlers in velvet.

lirg. 2. Buck No. 7, shot 17th June 1964, in hard horn.

lig. 3. Close-up of antler pedicle of Buck No. 11, shot 1st October 1964, to show ring of ostcoclastic activity beneath antler (arrowed).

FIG. 4. Dorsal view of antler pedicles of Buck No. 13, shot 18th 1)ecember 1964, showing stumps where new antlers will soon develop. 
level $(291 \mathrm{mg} / 100 \mathrm{~g}$ tissue) in mid-May, that of citric acid began to increase somewhat later and reached a maximum $(62 \mathrm{mg} / 100 \mathrm{~g}$ tissue $)$ only in July, that is, at the beginning of the rut. Both the concentration of fructose and citric acid exhibited a marked decline during the rut, the fall in fructose being much less precipitous than that in citric acid. The lowest values were recorded in January, when the seminal vesicles contained only $7 \mathrm{mg} / 100 \mathrm{~g}$ of fructose and $2 \mathrm{mg} / 100 \mathrm{~g}$ of citric acid.

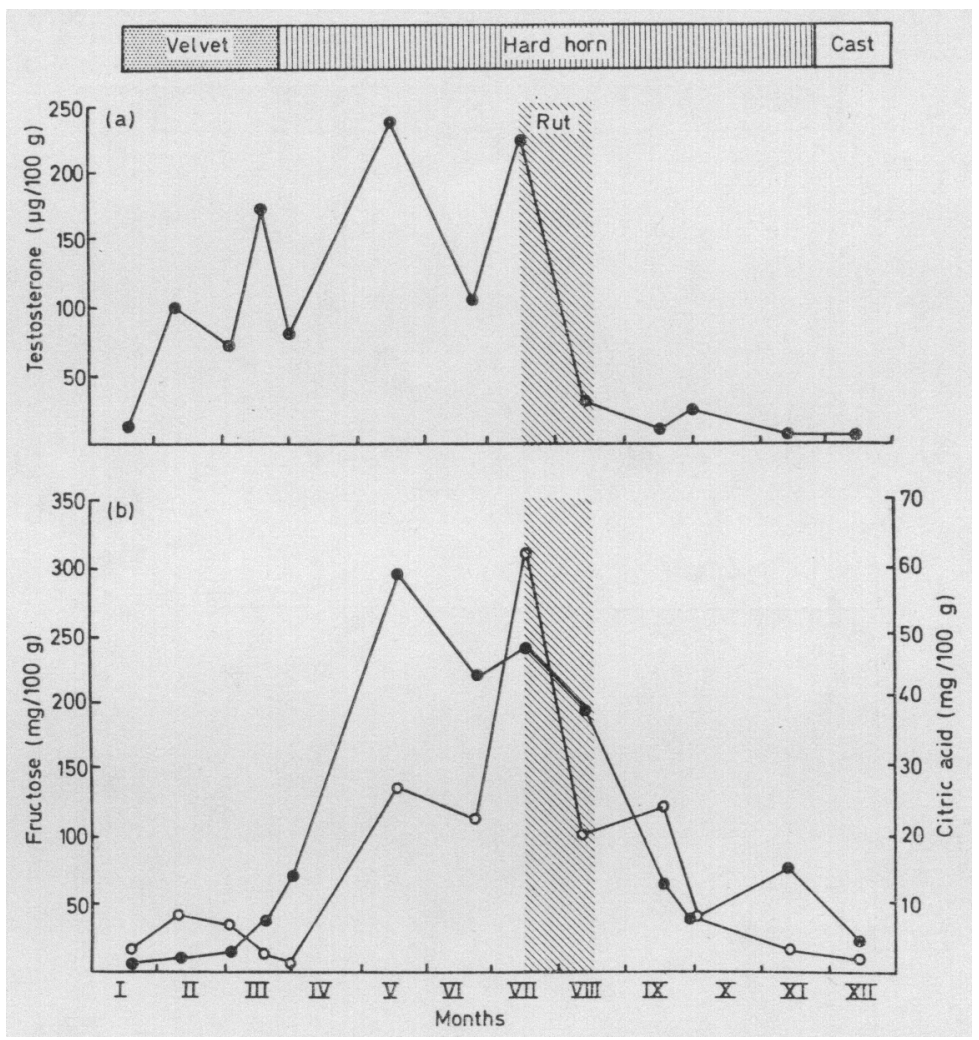

TEXT-FIG. 2. Seasonal changes in the concentration of (a) testosterone in the testes, and (b) of fructose ( ) and citric acid $(O)$ in the seminal vesicles of the roebuck. The period of rut is indicated by the vertical column; the state of the antlers (in velvet; hard horn; cast) by the horizontal bar at the top.

When the results of fructose and citric acid analyses are expressed in terms of content ( $\mathrm{mg} /$ total weight of seminal vesicles) instead of concentration, the curves representing the seasonal changes take on the shape shown in Textfig. 3. Using this method of presentation, it is possible to demonstrate that fructose and citric acid reach maximum values in the seminal vesicles in mid-July, at the onset of the rut.

The ampullae of the buck share with the seminal vesicles the ability to secrete fructose, and in that respect resemble many other species including man (Mann, 1964). In the thirteen animals in the present study, the concentration of fructose was persistently lower in the ampullae than in the seminal vesicles, the highest value (in mid-July) being $59 \mathrm{mg} / 100 \mathrm{~g}$ tissue. Citric acid 
was also present in the ampullae, the highest level $(24 \mathrm{mg} / 100 \mathrm{~g}$ tissue) again coinciding with the onset of the rut in mid-July.

Chromatographic evidence for the occurrence of sorbitol and inositol in the seminal vesicles

Using paper chromatography it has been possible to obtain confirmatory evidence for the occurrence of fructose in the roebuck's seminal vesicles. In addition to fructose, however, two other substances have been tentatively identified on the same paper chromatograms: one was inositol and the other sorbitol.
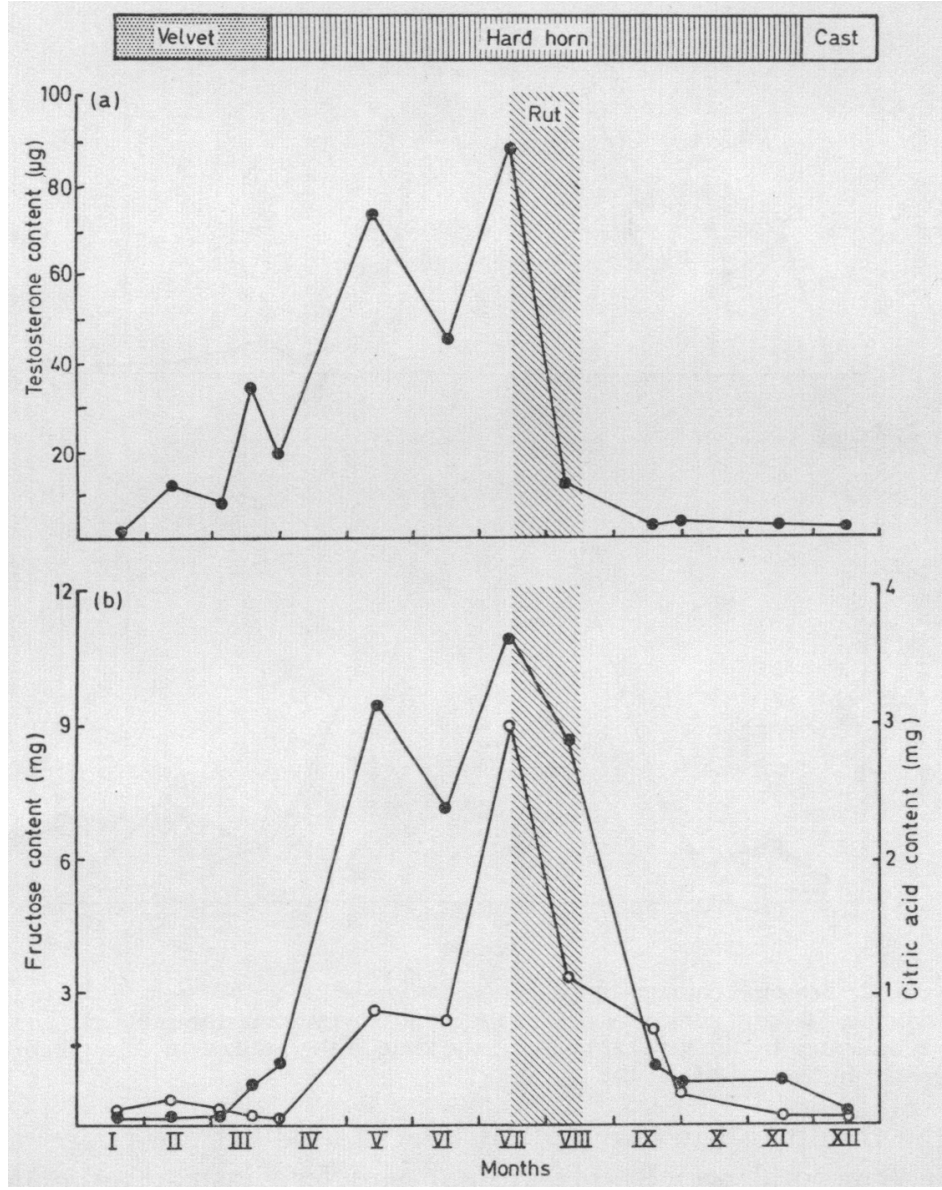

TEXT-Fig. 3. Seasonal changes in the content of (a) testosterone in the testes, and (b) fructose ( $)$ and citric acid $(O)$ in the seminal vesicles of the roebuck. The period of rut is indicated by the vertical column; the state of the antlers (in velvet; hard horn; cast) by the horizontal bar at the top.

For the purpose of identification, an ethanolic extract from $2.75 \mathrm{~g}$ seminal vesicle tissue was used, which yielded, after purification on the ion-exchange resin column, $3 \mathrm{ml}$ of a solution with a total content of $6.75 \mathrm{mg}$ fructose (as determined according to Mann, 1948), i.e. $11 \mathrm{mg}$ fructose $/ 5 \mathrm{ml}$. When $5 \mathrm{ml}$ of that material was applied to paper and chromatographed for $24 \mathrm{hr}$, three distinct silver-reducing spots were obtained. The strongest corresponded in $\mathbf{R}_{\mathbf{f}}$ 
value to fructose; the second, almost as intensely staining as the fructose spot, corresponded to sorbitol; and a third, by far the weakest, corresponded to inositol.

Correlation between structural and functional changes in the reproductive organs of the roebuck throughout the year

The following correlations have been established. The content of testosterone in the testes was significantly correlated with: (i) the weight of the seminal vesicles $(r=0.571, P<0.05)$; (ii) the content of fructose in the seminal vesicles $(r=0.616, P<0.05)$; and (iii) the content of citric acid in the seminal vesicles $(r=0.619, P<0.05)$. These correlations would have been much higher were it not for one or two values encountered at the beginning and end of the year, when the changes in the seminal vesicles lagged behind those in testicular testosterone by several weeks.

All the gross morphological, histological and chemical observations that have been made on the reproductive organs of the buck, show clearly that at the beginning of the year, in January, the male gonads are completely devoid of both exocrine and endocrine activity. They show no signs of spermatogenesis, their seminiferous tubules are at their smallest, and they contain hardly any testosterone at all. At that time, the seminal vesicles are also completely regressed and contain only trace amounts of fructose and citric acid. The antlers, however, are in early velvet and growing very rapidly indeed, presumably in response to the pituitary 'antler growth hormone' (Hall, Ganong, Taft \& Aub, 1960). By mid-February, however, there has been a considerable change. Primary spermatocytes have begun to appear in the testis, the seminiferous tubules have increased in diameter and an appreciable amount of testosterone is present. The accessory organs have apparently had no time as yet to respond to the testicular testosterone, and hence the weight of the seminal vesicles and their fructose and citric acid content remain low. The antlers are still in velvet and growing rapidly (Pl. 2, Fig. 1).

By mid-March, secondary spermatocytes have appeared, and there has been a further increase in the gross weight, tubular diameter and testosterone content of the testes. The seminal vesicles have now also shown a slight increase in both their size and fructose concentration, but not in the citric acid. The antlers are still in velvet and growing. Two weeks later, at the end of March, early spermatids have appeared in the continuously enlarging tubules, and the testosterone content of the testes is still high. In spite of this, the seminal vesicle response is not very pronounced, either in terms of weight or fructose concentration; the citric acid concentration has not risen at all. Yet, it seems that a significant amount of testosterone must already be circulating in the animal, since the velvet had just been shed. The animal will now remain in 'hard horn' (Pl. 2, Fig. 2) until the autumn.

In mid-May, approximately 2 months before the onset of the rut, the testes and epididymides contain abundant spermatozoa, and the animal would appear to be fertile. Nevertheless its testes, seminiferous tubules, testicular testosterone, seminal vesicles and vesicular fructose and citric acid go on increasing until the time of the rut itself. 
Perhaps the most interesting phase of the whole male 'cycle' is at the end of the rut, in mid-August. Although spermatogenesis is still active, and the testis weight has not fallen, there has nevertheless been a highly significant decrease in mean tubular diameter, and a precipitous fall in testicular testosterone content that is accompanied by regressive changes in the Leydig cells. A definite though much less pronounced fall has also occurred in the vesicular content of fructose and citric acid.

Some osteoclastic activity was apparent around the base of the antler pedicle in the two animals shot in the beginning of October and mid-November (Pl. 2, Fig. 3), and the one shot in December had cast its antlers completely (Pl. 2, Fig. 4). Tandler \& Grosz (1913) have shown that if a roebuck is castrated, the antlers are cast 2 to 4 weeks later. Presumably, the osteoclastic changes which we observed before casting must have also been the result of a testosterone deficiency, a conclusion which is in agreement with the finding that already during September and October the concentration of testosterone in the testes is very low indeed. In the three animals shot in October, November and December, there was also a marked reduction in the level of fructose and citric acid in the seminal vesicles. However, the decline lagged behind the falling levels of testicular testosterone, fructose reaching the baseline only in December, and citric acid in November.

\section{DISCUSSION}

Previous observations on the sexual cycle of the roebuck have been mainly concerned with the gross morphology and histology of the reproductive tract. An impressive study was carried out by Stieve (1950), who examined 273 bucks over a period of 40 years. Although our observations on testis weight are in agreement with his, Stieve was of the opinion that fertile matings could still occur even in December from reservoirs of spermatozoa stored in the epididymis long after spermatogenesis had ceased. In the few animals at our disposal, we could only find the occasional spermatozoon in the epididymis after midSeptember, and there were certainly not enough spermatozoa present for a fertile mating.

Brüggemann, Adam \& Karg (1965) also measured the weights of roebuck seminal vesicles throughout the year, with results similar to our own. In estimating the quantity of Leydig tissue in the testis, they found the highest values during the rut, with an abrupt fall immediately afterwards. This is once again very much in agreement with our own findings. They also determined the LH concentrations in the pituitary by the Parlow ovarian ascorbic acid depletion assay. The values appeared to rise up to the beginning of the rut, and fall sharply during the rut itself, only to rise again afterwards. The testicular testosterone results reported here would suggest that LH secretion was high before and during the rut, but fell towards the end of the rut, remaining low throughout the rest of the year. It is therefore difficult to relate the observations of Brüggemann et al. to our findings.

Lindner (1961) showed that in the bull there is a very close correlation between the content of testosterone in the testes and the secretion of testosterone 
into spermatic vein blood. If the same is also true of the roebuck, then the testicular testosterone values reported here are presumably a good index of testosterone secretion rates. The content of fructose and citric acid in the seminal vesicles appears to be less subject to individual variations than the content of testosterone in the testes. However, although significantly correlated with testicular testosterone, the vesicular fructose and citric acid rose less abruptly than testosterone in the spring, and fell more slowly than testosterone in the autumn. This could be due to several factors, one of which might be that a certain time must elapse between the onset of testicular testosterone secretion and the response of the seminal vesicles. Furthermore, one cannot expect the seminal vesicles to become immediately depleted of their secretory metabolites at the end of the rut, merely because the testosterone level has declined in the testes; factors such as individual variations in the storage capacity of the seminal vesicles, and the frequency of ejaculation, will also influence the rate of fructose and citric acid depletion.

It is interesting to relate the endocrine changes in the roebuck to the seasonal changes in antler growth. Development of the antler pedicle in the young buck during its first year of life is a secondary sexual characteristic, dependent on testicular activity; the presence of a pedicle is essential for subsequent antler development (Blauel, 1935; Wislocki et al., 1947). The antlers begin their development in early January, when the testis is at its most inactive state, and presumably neither FSH nor LH is being secreted by the pituitary. Shedding of the velvet in March or April is a consequence of the rising androgen levels (Wislocki et al., 1947). It is not known whether this is a central effect of testosterone, inhibiting the secretion of 'antler growth hormone' by the pituitary (Hall et al., 1960), or a direct effect on the blood vessels at the base of the antler pedicle, causing them to go into spasm. It is well recognized that castration of a buck when in velvet gives rise to a 'perruque head' (Tandler et al., 1913; Blauel, 1935), a condition in which the velvet is never shed and the antler keeps on growing in a completely disorganized manner.

It is a widely held belief amongst hunters that the head of an animal 'goes back', or becomes poorer, with increasing age. This could be a result of increased testicular activity giving rise to an earlier shedding of the velvet, thus causing a premature arrest of antler growth.

Casting of the antlers in November and December, and the osteoclastic activity at the base of the antler pedicle that precedes casting, are undoubtedly a result of the relative testosterone deficiency which starts at the end of the rut. Castration of a buck in hard horn, as opposed to one in velvet, results in casting of the antlers 2 to 4 weeks later (Tandler \& Grosz, 1913; Wislocki et al., 1947).

The changes in androgenic and spermatogenic activity of the buck's testes seem to be closely related events. Although the first increase in testicular testosterone content, in mid-February, precedes by 2 to 3 months the first appearance of spermatozoa in the testis, the first signs of meiotic activity can also be seen in the testis tubules in mid-February, suggesting a simultaneous release of FSH and LH by the pituitary. This situation is therefore analogous to that seen in the pubertal bull calf; small amounts of testosterone can be detected in the testes of 5- to 6-week old animals and high values are found by the age of 
5 to 6 months, but spermatozoa are seldom seen in the ejaculate before the bull is 8 to 9 months old (Davies, Mann \& Rowson, 1957; Lindner \& Mann, 1960; Hay, Lindner \& Mann, 1961). However, the roebuck does not appear to undergo a comparable change in the androstenedione-testosterone ratio in the testis, such as is seen in the bull calfjust before puberty.

Just as the onset of pituitary fsh and in secretion appears to occur simultane ously in the spring, so the secretion of both hormones appears to decline simultaneously at the end of the rut. There is a highly significant decrease in mean testis tubular diameter that coincides with the abrupt fall in testicular testosterone content. However, it takes almost 2 months before spermato genesis has stopped completely, whereas testosterone secretion ceases quite abruptly.

Finally, it is interesting to correlate the seasonal sexual changes in the buck with the corresponding events in the doe. After mating in July or August, the doe enters a 5-month period of delayed implantation, during which time her corpus luteum appears to be secreting normal amounts of progesterone (Short 6 Hay, 1966). This period of delayed implantation corresponds to the phase of testicular regression in the buck. Delayed implantation in the doe is terminated at the end of December, possibly as a result of ovarian oestrogen secretion; paradoxically, at this time the buck has reached the nadir of his sexual activity. Birth of the kids takes place in May, at a time when the buck has just become fertile, and the onset of the rut about 2 months later is presumably due to the occurrence of oestrus in the doe. It is not known whether the doe is monoestrous, or seasonally polyoestrous; Stieve (1950) was of the opinion that some does might still come into oestrus at any time from September to December, thus accounting for the so-called 'second rut' and late fertile matings that he ob served. Further work is clearly required to clarify this aspect of the reproductive cycle.

\section{ACKNOWLEDGMENTS}

We would like to thank the Forestry Commission for permission to shoot roe bucks throughout the year, and Mr Rex Whitta for actually shooting the animals in accordance with our wishes; without his help and skill, this study would not have been possible. Dr R. C. Campbell kindly carried out the statistical cal culations for us, and Dr Mary Hay helped in the histological interpretation of the testis sections. Mr D. Rottenberg and Mrs Rosemary Lincoln gave invalu able holn with analyses in the lahnratory; Mrs Jnsephine Patten took the photn graphs for Plate 2, and Miss Jane Mavrogordato typed the manuscript. The work was aided by the Agricultural Research Council and the Rockefeller Foundation.

\section{REFERENCES}

Blauel, G. (1935) Beobachtungen über die Enstehung der Perücke beim Rehbock. Endokrinologie, 15, 321.

Brüggemann, J., Adam, A. \& KARg, H. (1965) ICSH-bestimmungen in Hypophysen von Rehböcken (Capreolus capreolus) und Hirschen (Cervus elaphus) unter Berücksichtingung des Saisoneinflusses. Acta endocr., Copenh. 48, 569. 
Davies, D. V., Mann, T. \& Rowson, L. E. A. (1957) Effect of nutrition on the onset of male sex hormone activity and sperm formation in monozygous bull-calves. Proc. $R$. Soc. B, $147,332$.

Hall, T. C., Ganong, W. F., Taft, E. B. \& Aub, J. G. (1960) Endocrine control of deer antler growth. Acta endocr., Copenh. Suppl. 51, 525.

Hay, M. F., Lindner, H. R. \& ManN, T. (1961) Morphology of bull testes and seminal vesicles in relation to testicular androgens. Proc. $R$. Soc. B, 154, 433.

King, J. M., Short, R. V., Mutton, D. E. \& Hamerton, J. L. (1966) The reproductive physiology of male zebra-horse and zebra-donkey hybrids. Symp. zool. Soc. Lond. 15, 511.

Lindner, H. R. (1961) Androgens and related compounds in the spermatic vein blood of domestic animals. I. Neutral steroids secreted by the bull testis. 7. Endocr. 23, 139.

Lindner, H. R. \& MANN, T. (1960) Relationship between the content of androgenic steroids in the testes and the secretory activity of the seminal vesicles in the bull. F. Endocr. $21,341$.

Mann, T. (1948) Fructose content and fructolysis in semen. Practical application in the evaluation of semen quality. 7. agric. Sci. 38, 323.

MANN, T. (1964) Biochemistry of semen and of the male reproductive tract. Methuen, London,

Mann, T. \& Rottenberg, D. A. (1966) The carbohydrate of human semen. F. Endocr. $34,257$.

Short, R. V. \& HAY, M. F. (1966) Delayed implantation in the roe deer, Capreolus capreolus. Symp. zool. Soc. Lond. 15, 173.

Short, R. V. \& MANN, T. (1965) Androgenic activity in a seasonally breeding animal, the roe buck (Capreolus capreolus). F. Endocr. 31, xix.

Stieve, H. (1950) Anatomisch-biologische Untersuchungen über die Fortpflanzungstätigkeit des europäischen Rehes (Capreolus capreolus capreolus L.). Z. mikrosk.-anat. Forsch. 55, 427.

TANdler, J. \& Grosz, S. (1913) Die biologischen Grundlagen der sekundären Geschlechtscharaktere. Springer, Berlin.

Taylor Page, F. J. (1962) Roe deer. Sunday Times Publications, London.

Trevelyan, W. E., Procter, D. P. \& Harrison, J. S. (1950) Detection of sugars on paper chromatograms. Nature, Lond. 166, 444.

WisLocki, G. B. (1943) Studies on growth of deer antlers. 2. Seasonal changes in the male reproductive tract of the Virginia deer (Odocoileus virginianus borealis) with a discussion of the factors controlling the antler-gonad periodicity. Essays in Biology in Honour of H. M. Evans, p. 631. University of California Press.

Wislocki, G. B., Aub, J. C. \& Waldo, C. M. (1947) The effects of gonadectomy and the administration of testosterone propionate on the growth of antlers in male and female deer. Endocrinology, 40, 202. 